\title{
Specific variations of the atmospheric electric field potential gradient as a possible precursor of Caucasus earthquakes
}

\author{
N. Kachakhidze ${ }^{1}$, M. Kachakhidze ${ }^{1}$, Z. Kereselidze ${ }^{2}$, and G. Ramishvili ${ }^{3}$ \\ ${ }^{1}$ Tbilisi State University, 3, I. Chavchavadze av., 0128, Tbilisi, Georgia \\ ${ }^{2}$ Nodia Institute of Geophysics, 1, Alexidze str., 0183, Tbilisi, Georgia \\ ${ }^{3}$ I. Chavchavadze University, National Astrophysical Observatory, 2, Kazbegi av., 0160, Tbilisi, Georgia
}

Received: 20 October 2008 - Revised: 12 June 2009 - Accepted: 12 June 2009 - Published: 22 July 2009

\begin{abstract}
The subject of the research is the study of anomalous disturbances of the gradient of electric field potential of the atmosphere as possible precursors of earthquakes.

In order to reveal such precursor Dusheti observatory ( $\varphi=42.05 ; \lambda=44.42)$ records of electric field potential's gradient (EFPG) of the atmosphere are considered for 41 earthquakes $(M \geq 5.0)$ occurrence moments in the Caucasus region.

Seasonal variations of atmospheric electric field potential gradient and inter overlapping influence of meteorological parameters upon this parameter are studied. Original method of "filtration" is devised and used in order to identify the effect of EFPG "clear" anomalies.

The so-called "clear" anomalies are revealed from $(-148.9 \mathrm{~V} / \mathrm{m})$ to $188.5 \mathrm{~V} / \mathrm{m}$ limits and they are connected with occurrence moments of 29 earthquakes out of 41 discussed earthquakes (about 71\%). "clear" anomalies manifest themselves in 11-day precursor window.

Duration of anomalies is from 40 to $90 \mathrm{~min}$.
\end{abstract}

\section{Introduction}

When earthquake problems are investigated it should be taken into consideration that enough knowledge and information about the process of earthquake preparation are not available yet. So we have to use indirect method, it means, to observe all those phenomena which accompany complex process of earthquake preparation in the seismosphere.

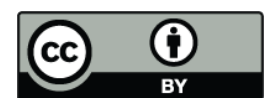

Correspondence to: N. Kachakhidze (ninokachakhidze@rambler.ru)
Earthquake preparation on the Earth's surface is mainly expressed by anomalous changes of various geophysical fields, though earthquake precursors do not always manifest themselves due to peculiarities of geophysical structure of source area and complex geophysical processes which take place in the source (Park et al., 1993; Plotkin, 2003; Pulinet, 2005; Prasad et al., 2000; Pulinets et al., 2006; Ouzounov et al., 2007).

We consider investigation of atmospheric electric precursor as important stage of earthquake problem.

Many scientific articles have considered anomalous disturbances of characteristic parameters of atmospheric electric field in earthquake preparation period. In many works near-ground atmospheric layer is considered as "transmission" layer between the Earth and the ionosphere (Gufeld et al., 1988; Molchanov et al., 1993, 1998, 2001; Hayakawa et al., 2000; Kachakhidze, 2000; Smirnov, 2008).

Amplitudes of EFPG disturbances are several times larger that average value of this parameter. It is obvious that determination of EFPG precursor time is problematic task (Liperovsky et al., 2008; Triantis et al., 2008).

Examination of contemporary investigations enables us to note that perfect theoretical model of such important phenomenon as atmospheric electric precursor of an earthquake, is not yet constructed.

\section{Data}

Our aim is to investigate "seismic share" in anomalous disturbances of atmospheric electric field.

We have considered change of EFPG near-ground layer of the atmosphere some days before earthquake occurrence.

Published by Copernicus Publications on behalf of the European Geosciences Union. 
Table 1. Catalogue of the Caucasus 1956-1991 earthquakes with $\mathrm{M} \geq 5.0$.

\begin{tabular}{|c|c|c|c|c|c|c|c|}
\hline $\mathrm{N}$ & year & mnth & data & $\mathrm{h}$ & M & $\varphi$ & $\lambda$ \\
\hline 1 & 1956 & 3 & 21 & 4 & 5.3 & 40.9 & 48.4 \\
\hline 2 & 1957 & 1 & 29 & 15 & 5.3 & 42.4 & 42.4 \\
\hline 3 & 1957 & 7 & 2 & 0 & 6.5 & 36 & 52.5 \\
\hline 4 & 1958 & 5 & 6 & 4 & 5.5 & 43.1 & 47.8 \\
\hline 5 & 1959 & 5 & 20 & 19 & 5.1 & 41.9 & 41.8 \\
\hline 6 & 1963 & 1 & 27 & 19 & 6.2 & 41.1 & 49.8 \\
\hline 7 & 1963 & 7 & 16 & 18 & 6.4 & 43.2 & 41.6 \\
\hline 8 & 1965 & 8 & 31 & 7 & 5.3 & 39.6 & 40.8 \\
\hline 9 & 1966 & 4 & 20 & 16 & 5.4 & 41.8 & 48.1 \\
\hline 10 & 1966 & 4 & 27 & 19 & 5 & 38.2 & 42.5 \\
\hline 11 & 1966 & 5 & 2 & 23 & 5 & 38 & 42.4 \\
\hline 12 & 1966 & 8 & 19 & 12 & 6.8 & 39.2 & 41.5 \\
\hline 13 & 1967 & 7 & 26 & 18 & 5.8 & 39.8 & 40.3 \\
\hline 14 & 1968 & 4 & 29 & 17 & 5.4 & 39.2 & 44.2 \\
\hline 15 & 1968 & 10 & 5 & 15 & 5.4 & 41.7 & 49.5 \\
\hline 16 & 1969 & 6 & 17 & 23 & 5.1 & 43.3 & 45.2 \\
\hline 17 & 1971 & 5 & 22 & 16 & 6.8 & 38.8 & 40.5 \\
\hline 18 & 1973 & 12 & 14 & 9 & 5.1 & 41.9 & 49 \\
\hline 19 & 1974 & 8 & 4 & 15 & 5.1 & 42.2 & 45.9 \\
\hline 20 & 1975 & 1 & 9 & 23 & 5.2 & 43.1 & 47.1 \\
\hline 21 & 1976 & 2 & 7 & 3 & 5 & 40.4 & 51.1 \\
\hline
\end{tabular}

The problem is processed on the basis of retrospective data, keeping to the chronology of Caucasian earthquakes.

The Caucasus is a seismoactive region of transasian zone. Earthquakes occur here frequently. Many of them have caused serious damages and human victims.

Since 1900 year more than 30 earthquakes with magnitude $M \geq 6.0$ are recorded in the Caucasus.

We have studied Dusheti observatory's $(\varphi=42.05$; $\lambda=44.42)$ EFPG records by hours (1956-1991 years) with respect to 41 Caucasian earthquakes $(M \geq 5.0)$ occurrence moments. Table 1 gives the list of considered earthquakes.

It should be noted that systematic observation of EFPG was carried out in the region since 1956 year, but in 1992 year observation was ceased due to certain objective reasons.

According to many scientific works, EFPG anomalies changes, as earthquake precursors, manifest themselves several days or hours before an earthquake. Experience of similar investigation carried out for the Caucasian earthquakes
Table 1. Continued.

\begin{tabular}{|c|c|c|c|c|c|c|c|}
\hline $\mathrm{N}$ & year & mnth & data & $\mathrm{h}$ & M & $\varphi$ & $\lambda$ \\
\hline 22 & 1976 & 3 & 25 & 11 & 5 & 41 & 42.8 \\
\hline 23 & 1976 & 7 & 27 & 18 & 5 & 40.1 & 48.6 \\
\hline 24 & 1976 & 7 & 28 & 20 & 6.2 & 43.2 & 45.6 \\
\hline 25 & 1977 & 9 & 30 & 16 & 5.4 & 40.1 & 45 \\
\hline 26 & 1977 & 12 & 15 & 15 & 5 & 43.2 & 45 \\
\hline 27 & 1978 & 1 & 2 & 6 & 5.3 & 41.4 & 44.1 \\
\hline 28 & 1978 & 5 & 26 & 13 & 5.3 & 41.6 & 46.0 \\
\hline 29 & 1980 & 5 & 4 & 18 & 6.2 & 37.8 & 49.1 \\
\hline 30 & 1981 & 10 & 18 & 5 & 5.4 & 43.3 & 45.4 \\
\hline 31 & 1983 & 10 & 30 & 4 & 6.8 & 40 & 41.6 \\
\hline 32 & 1984 & 3 & 4 & 10 & 5.2 & 42.9 & 45.5 \\
\hline 33 & 1984 & 9 & 18 & 13 & 5.1 & 40.9 & 42.1 \\
\hline 34 & 1985 & 7 & 4 & 5 & 5.1 & 42 & 45.6 \\
\hline 35 & 1986 & 3 & 6 & 0 & 6.1 & 40.1 & 51.6 \\
\hline 36 & 1986 & 5 & 13 & 8 & 5.6 & 41.4 & 43.7 \\
\hline 37 & 1988 & 12 & 7 & 7 & 6.9 & 40.9 & 44.2 \\
\hline 38 & 1989 & 8 & 3 & 7 & 5 & 43.5 & 45.2 \\
\hline 39 & 1989 & 9 & 16 & 2 & 6.3 & 40.3 & 51.6 \\
\hline 40 & 1990 & 12 & 16 & 15 & 5.1 & 41.3 & 43.8 \\
\hline 41 & 1991 & 4 & 29 & 9 & 6.9 & 42.4 & 43.7 \\
\hline
\end{tabular}

(Kachakhidze., 2000) enabled us to consider 11-day precursory window (the 11-th day is the day of earthquake occurrence).

\section{Data analysis}

General consideration of EFPG data in connection of occurrence moment of the Caucasian earthquakes shows anomalous changes of EFPG values in quite large limits; though, we can not consider them as anomalies disturbances caused by only one factor (by earthquake preparation process) - we should take into account all factors which may affect atmospheric EFPG value.

Knowing the nature of atmosphere's electric field, we should pay attention to its seasonal background values first of all.

All data of potential gradient were classified according to months and average quantity of background value of 
Table 2. Seasonal background of the atmospheric EFPG (V/m) for Dusheti observatory.

\begin{tabular}{lllllll}
\hline month & $\bar{X}-\sigma$ & $\bar{X}+\sigma$ & $\bar{X}-2 \sigma$ & $\bar{X}+2 \sigma$ & $\bar{X}-3 \sigma$ & $\bar{X}+3 \sigma$ \\
\hline 1 & -0.40098 & 25.01023 & -12.9745 & 37.67179 & -25.636 & 50.33336 \\
2 & -3.58406 & 23.78167 & -17.2669 & 37.46453 & -30.9498 & 51.1474 \\
3 & -3.12577 & 20.0413 & -14.0526 & 31.17118 & -24.9795 & 42.30106 \\
4 & -11.2838 & 23.43706 & -28.4034 & 40.65468 & -45.523 & 57.87229 \\
5 & -27.273 & 42.20281 & -62.011 & 76.94074 & -96.7489 & 111.6787 \\
6 & -15.1669 & 26.48896 & -35.457 & 46.71078 & -55.7471 & 66.93259 \\
7 & -18.1554 & 27.65535 & -41.0607 & 50.56071 & -63.9661 & 73.46606 \\
8 & -15.2063 & 26.09792 & -35.8584 & 46.75003 & -56.5106 & 67.40215 \\
9 & -4.46336 & 17.57884 & -15.4845 & 28.59993 & -26.5056 & 39.62103 \\
10 & -1.93289 & 14.45555 & -9.54261 & 21.79281 & -17.1523 & 29.13008 \\
11 & -3.235 & 20.09864 & -14.9018 & 31.76546 & -26.5686 & 43.43228 \\
12 & -0.07877 & 22.67574 & -11.3591 & 33.76237 & -22.6395 & 45.04275 \\
\hline
\end{tabular}

atmospheric electric field potential gradient was calculated for each month

$s^{2}=\sum \omega_{i}\left[\left(x_{i}\right)^{2}-(\bar{x})^{2}\right] \quad \sigma=\sqrt{s^{2}}$

where $x_{i}$ is average quantity of potential gradient according a month, $\omega_{i}$ is relative frequency of $x_{i}$ data, $\mathrm{s}$ and $\sigma$ are dispersion and deviation correspondingly.

Table 2 gives EFPG seasonal background values according months. In the second stage we have calculated the following quantities: $\bar{x} \pm \sigma, \bar{x} \pm 2 \sigma$ and $\bar{x} \pm 3 \sigma$ for 11-day EFPG data in connection with occurrence moments of all considered 41 earthquakes. It is known that $\bar{x} \pm 3 \sigma$ requirement is stringent - it excludes all "randomness".

By cutting $\bar{x} \pm \sigma$ quantity off EFPG values we received change of anomalies from (-281.7) V/m to $242.3 \mathrm{~V} / \mathrm{m}$ (in all cases of 41 earthquakes). More stringent requirement (cutting off $\bar{x} \pm 2 \sigma$ ) gives us limits of EFPG changes from $(-247) \mathrm{V} / \mathrm{m}$ to $219.4 \mathrm{~V} / \mathrm{m}$ (in case of 40 earthquakes) and in conditions of third requirement (cutting off $\bar{x} \pm 3 \sigma$ quantity) the rest of anomalies change from $(-212.3) \mathrm{V} / \mathrm{m}$ to 196.5 $\mathrm{V} / \mathrm{m}$ (in case of 36 earthquakes).

Anomalies, which are received by cutting off $\bar{x} \pm \sigma, \bar{x} \pm 2 \sigma$ and $\bar{x} \pm 3 \sigma$ quantities, are named as "usual" anomalies of I, II and III types correspondingly.

\section{Discussion}

The problem of meteorological parameters' influence upon EFPG quantities appeared after the above mentioned analysis.

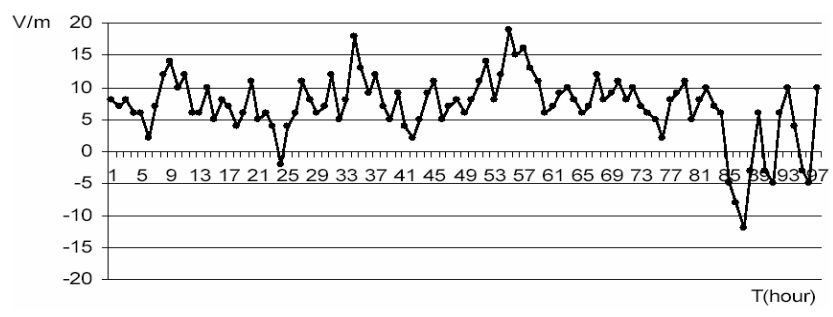

Fig. 1. Distribution of atmospheric EFPG for 4 normal weather days (7 July 1987-11 July 1987).

It is known that average annual quantity of atmospheric EFPG for Dusheti observatory is about $84 \mathrm{~V} / \mathrm{m}$ in normal day conditions (low clouds amount is not more than 4 , wind velocity is $4 \mathrm{~m} / \mathrm{sec}$ or less, and there are no precipitations, thunders and lightings).

Figure 1 shows EFPG distribution according to hours during four normal days (7 July 1987-11 July 1987).

(Real quantities of EFPG are reduced to one-tenth in figures).

Unfortunately it was found out that normal weather days coincide with earthquake precursor periods, which were considered by us, very seldom.

Meteorological parameters can change quantities of atmospheric EFPG considerably.

Figure 2 shows EFPG distribution according to hours in bad weather conditions (four days from 22 October 1987 to 26 October 1987). In these concrete days average low and $\mathrm{CB}$ clouds, average wind, average precipitation, average temperature, average relative and absolute humidity were registered. 
Table 3. Three groups of the meteorological parameters.

\begin{tabular}{llll}
\hline cloud (low tier \& CB) & (ball) & wind & $(\mathrm{m} / \mathrm{sec})$ \\
\hline 1. low & $\mathrm{K}<3$ & 1. weak & $\mathrm{K}<5$ \\
2. average & $3 \leq \mathrm{K}<5$ & 2. moderate & $5 \leq \mathrm{k}<15$ \\
3. high & $\mathrm{K} \geq 5$ & 3. strong & $\mathrm{K} \geq 15$ \\
\hline precipitation & $(\mathrm{mm})$ & air temperature & $\left(\mathrm{C}^{0}\right)$ \\
\hline 1. weak & $\mathrm{O} .1 \leq \mathrm{K}<1$ & 1. low & $-14 \leq \mathrm{K}<0$ \\
2. moderate & $1 \leq \mathrm{K}<5$ & 2. average & $0 \leq \mathrm{K}<25$ \\
3. strong & $\mathrm{K} \geq 5$ & 3. high & $\mathrm{K} \geq 25$ \\
\hline relative moisture & $(\%)$ & absolute moisture & $(\mathrm{mlbr})$ \\
\hline 1. low & $0 \leq \mathrm{K}<40$ & 1. low & $0 \leq \mathrm{K}<5$ \\
2. average & $40 \leq \mathrm{K}<70$ & 2. average & $5 \leq \mathrm{K}<15$ \\
3. high & $\mathrm{K} \geq 70$ & 3. high & $\mathrm{K} \geq 15$ \\
\hline
\end{tabular}

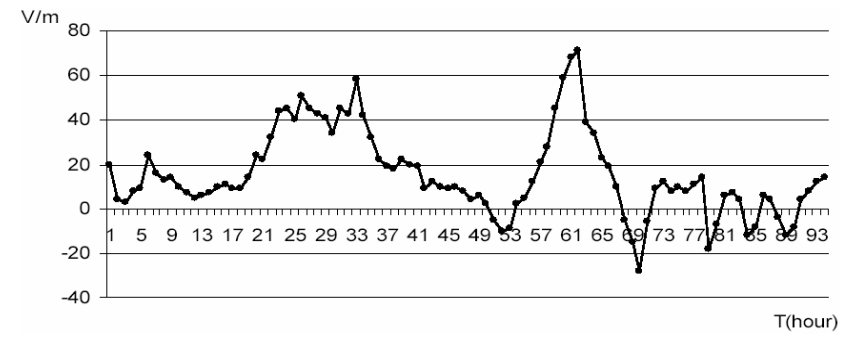

Fig. 2. Distribution of atmospheric EFPG for 4 bad weather days (22 October 1987 to 126 October 1987).

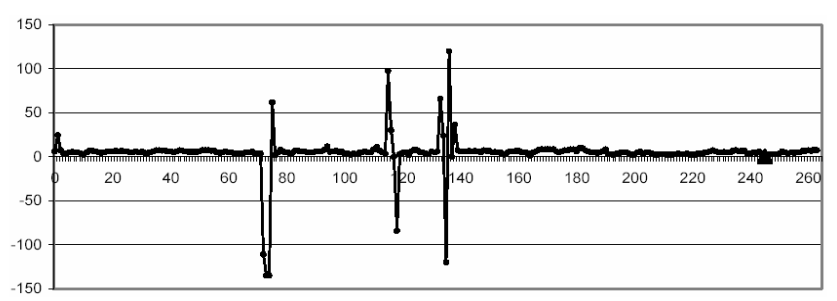

Fig. 3. Distribution of atmospheric EFPG by hours for bad weather days with 2 July 1957 earthquake occurrance moment (triangle moment of the earthquake occurrence, by horizontal axis - time before earthquake occurrance in hours, by vertical axis - atmospheric EFPG in $\mathrm{V} / \mathrm{m}$ ).

Figure 3 and Fig. 4 give examples of EFPG distributions by hours in connection of 2 July $1957(\mathrm{M}=6.5)$ and 16 December 1990 (M=5.1) earthquakes occurrence moments mainly in bad and normal weather days correspondingly.

We should note that in the precursors revealing process it is no good to estimate influence of only one meteorologi-

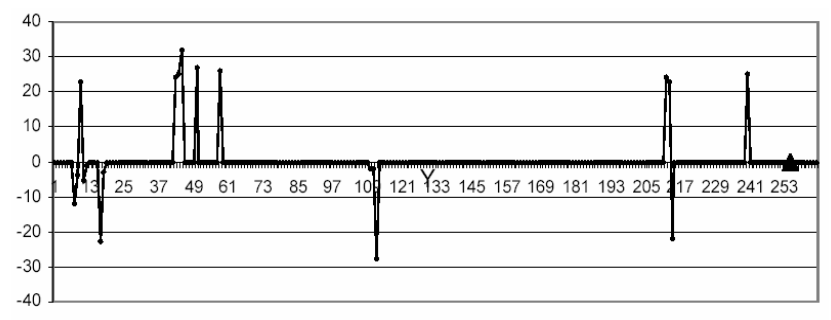

Fig. 4. Distribution of atmospheric EFPG by hours for normal weather days with 16 December 1990 earthquake occurrance moment.

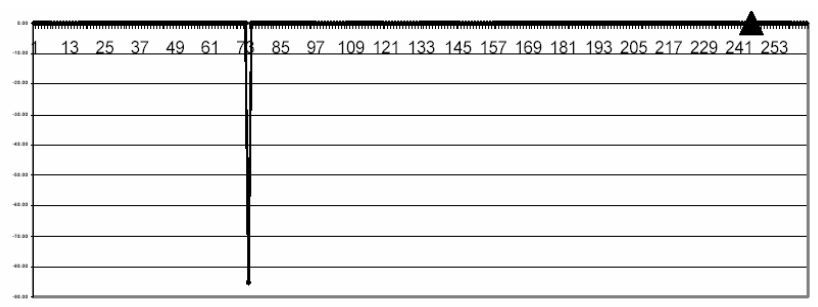

Fig. 5. Atmospheric EFPG III kind "clear" anomaly with respect to 2 July 1957 earthquake occurrance moment.

cal parameter upon EFPG because all parameters have inter overlapping property. So we had to consider the problem for real weather combinations.

In order to identify "clear" anomalies connected with earthquakes, we have considered 7 basic meteorological parameters: 1. low clouds, 2. CB clouds, 3. precipitations, 4. wind, 5. air temperature, 6. relative humidity and 7. 


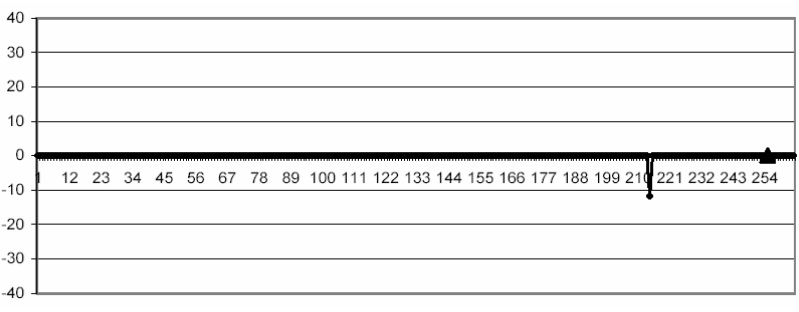

Fig. 6. Atmospheric EFPG III kind "clear" anomaly with respect to 16 December 1990 earthquake occurrance moment.

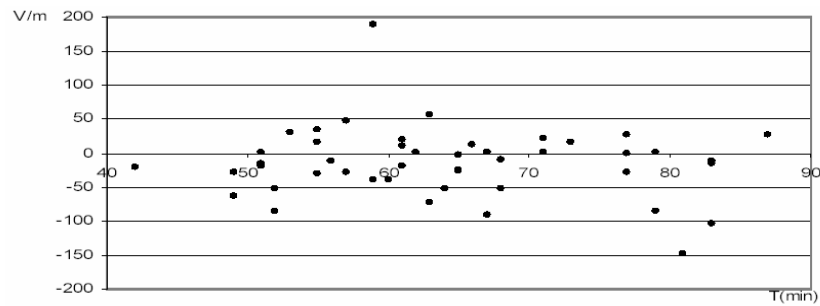

Fig. 7. Distribution of EFPG anomalies with respect to their durations.

absolute humidity. Besides these parameters we have considered cases of thunders and lightings.

In order to exclude inter overlapping influence of meteorological parameters we have performed the following analysis for EFPG quantities:first of all we have paid attention to cases of thunders and lightings and estimated corresponding atmospheric EFPG. We have established that EFPG corresponding quantities vary between $(-2500) \mathrm{V} / \mathrm{m}$ and $3000 \mathrm{~V} / \mathrm{m}$ limits for Dusheti observatory.

All disturbances of atmospheric EFPG, which were provoked by thunders and lightings, were disregarded.

On the next stage we have made attempts to estimate EFPG anomalous disturbances which were caused by above mentioned 7 basic meteorological parameters. Each meteorological parameter was divided into three groups: high (strong), average (moderate) and low (weak).

So we have received 21 "sorted out" meteorological parameters instead of 7 (Table 3).

On the basis of new 21 meteorological parameters we have created so-called "weather combinations" in the following way: in case of fixed quantity of one meteorological parameter (for example, weak wind) we have considered such weather combination when all other meteorological parameters are strong or high.

On the next stage, in case of the same value of the same parameter (weak wind), we have considered new weather combination, when the rest of parameters, except one (for example, precipitation) are high or strong, but precipitation is moderate.

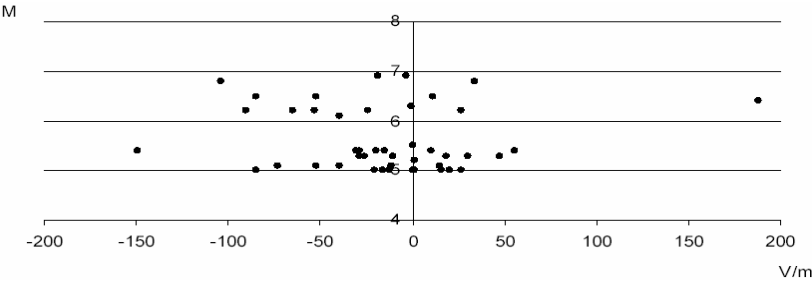

Fig. 8. Distribution of EFPG anomalies with respect to earthquakes magnitude.

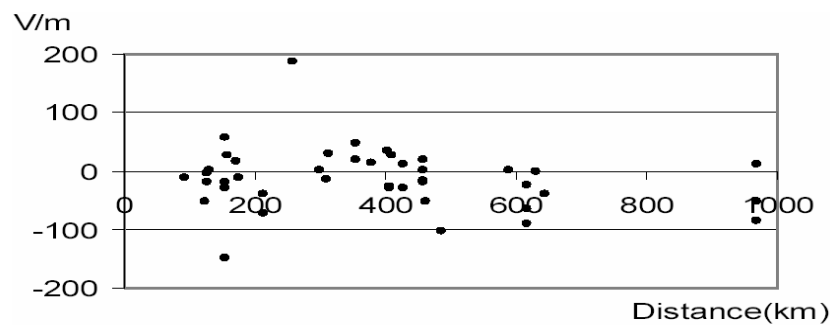

Fig. 9. Distribution of EFPG anomalies with respect to the epicentral distance (from Dusheti).

As a result we have received

$\frac{n !}{k !(n-k) !}=2187$

combination where none of possible variants is omitted.

Creation of so-called weather combinations enabled us to estimate corresponding average quantities of EFPG and only then we have returned to previously identified by us "usual" anomalies of I, II and III type and filtrated anomalies.

Namely, values of I, II and III type "usual" anomalies were compared with corresponding EFPG quantities of weather combinations of the same period.

Due to such filtration we have received new anomaly of I type (40 earthquakes) which changes from $(-183.1) \mathrm{V} / \mathrm{m}$ to $234.3 \mathrm{~V} / \mathrm{m}$.

In the same way we have received new anomalies of II type (32 earthquakes) and III type (29 earthquakes) with anomalous changes of EFPG from (-166) V/m to $211.4 \mathrm{~V} / \mathrm{m}$ and from $(-148.9) \mathrm{V} / \mathrm{m}$ to $188.5 \mathrm{~V} / \mathrm{m}$ correspondingly.

Anomalies of I, II and III type, which were received by filtration, are named as "clear" anomalies of I, II and III type.

Figures 5 and 6 show examples of "clear" anomalies of III type with respect to occurrence moments of above mentioned 2 July 1957 year and 16 December 1990 earthquakes.

Duration of III type "clear" anomalies vary from 40 to 90 min. We have tried to reveal correlation between EFPG anomalies and their durations (Fig. 7), precursor time distributions (as III type "clear" anomalies function) and earthquake magnitudes (Fig. 8), precursor time and epicentral distances (from Dusheti Observatory) (Fig. 9).

Just like other authors (Smirnov, 2008), we have not revealed any interesting relations for Caucasian region. 


\section{Conclusions}

To our opinion all classes of "clear" anomalies are important, but "clear" anomaly of III type is the most significant because all randomness and disturbances due to weather effect were excluded while its revealing. "clear" anomalies are spread in 11-day period with respect to earthquake occurrence moments, but in many cases they manifest themselves in 4 days period. Quantity of III type "clear" anomaly varies from $(-148.9) \mathrm{V} / \mathrm{m}$ to $188.5 \mathrm{~V} / \mathrm{m}$.

According to the above said "clear" anomaly of III type is recognized as earthquake precursor. This precursor is revealed in 29 cases (71\%) out of 41 discussed earthquakes of the Caucasus.

Edited by: M. Contadakis

Reviewed by: P. F. Biagi and another anonymous referee

\section{References}

Gufeld, I. P. and Shuleikin, V. J.: Variations of atmospheric field during earthquakes preparing, Earth Physics, 2, 12-16, 1988.

Hayakawa, M., Kopytenko, Y., Smirnova, N., Troyan, V., and Peterson, T. H.: Monitoring ULF magnetic disturbances, and schemes for recognizing earthquake precursors, Phys. Chem. Earth A, 25, 3, 263-269, 2000.

Kachakhidze, N. K.: Electrical field potential gradient of atmosphere as a possible precursor of earthquakes, Bulletin of Georgian Academy of Sciences, 161, N3, 32-43, 2000.

Liperovsky, V. A., Meister, C. V., Liperovskaya, E. V., and Bogdanov, V. V.: On the generation of electric field and infrared radiation in aerosol clouds due to radon emanation in the atmosphere before earthquakes, Nat. Hazards Earth Syst. Sci., 8, 1199-1205, 2008 , http://www.nat-hazards-earth-syst-sci.net/8/1199/2008/.

Molchanov, O. A., Mazhaeva, O. A., Golyavin, A. N., and Hayakawa, M.: Observation by the Intercosmos-24 Satellite of ELF-VLF electromagnetic emissions associated with earthquakes, Ann. Geophys., Atmos. Hydrospheres Space Sci., 11, 5, 431-440, 1993.
Molchanov, O. A. and Hayakawa, M.: On the generation mechanism of ULF seismogenic electromagnetic emissions, Physics of the Earth and Planetary Interiors, 105, 201-220, 1998.

Molchanov,O., Kulchitsky, A., and Hayakawa M.: Inductive seismo-electromagnetic effect in relation to seismogenic ULF emission, Nat. Hazards Earth Syst. Sci., 1, 61-67, 2001, http://www.nat-hazards-earth-syst-sci.net/1/61/2001/.

Ouzounov, D., Defu, L., Chunli, K., Cervone,G., Kafatos, M., and Taylor, P.: Outgoing long wave radiation variability from IR satellite data prior to major earthquakes, Tectonophysics, 431, 211-220, 2007.

Park, S. K., Johnston, M. J. S., Madden, T. R., Morgan, F. D., and Morrison. Electromagneticprecursors to earthquakes in the ulfband, Rev. Geophys., 31, 2, 117-132, 1993.

Plotkin, V. V.: GPS detection of ionospheric perturbation before the 13 February 2001, Salvador earthquake, Nat. Hazards Earth Syst. Sci., 3, 249-253, 2003, http://www.nat-hazards-earth-syst-sci.net/3/249/2003/.

Prasad, B. S. N., Nagaraja, T. K.,Chandrashekara, M. S., Paramesh, L., and Madhava, M. S.: Diurnal and seasonal variations of radioactivity and electrical conductivity near the surface for a continental location Mysore, India, Atmos. Res., 76, 65-77, 2000.

Pulinets, S. A., Ciraola, L., and Joyva, A.: Ionospheric anomalies registered round the time of several strong earthquakes in United States. The physics of seismic electric signals - Solid State Section. Departmnt of physics, University of Athens, Athens, Creece, 388, 2005.

Pulinets, S. A., Ouzounov, D., Karelin, A. V., Boyarchuk, K. A., and Pokhmelnykh, L. A.: The physical nature of the thermal anomalies observed before strong earthquakes, Phys. Chem. Earth, 31, 143-153, 2006.

Smirnov, S.: Association of the negative anomalies of the quasistatic electric field in atmosphere with Kamchatka seismicity, Nat. Hazards Earth Syst. Sci., 8, 745-749, 2008, http://www.nat-hazards-earth-syst-sci.net/8/745/2008/.

Triantis, D., Anastasiadis, C., and Stavrakas, I.: The correlation of electrical charge with strain on stressed rock samples, Nat. Hazards Earth Syst. Sci., 8, 1243-1248, 2008, http://www.nat-hazards-earth-syst-sci.net/8/1243/2008/. 